OPEN ACCESS

Edited by:

Hidetaka Hamasaki,

Hamasaki Clinic, Japan

Reviewed by:

Gerit Schernthaner,

Medical University of Vienna, Austria

Michael Edwin Edmonds,

King's College Hospital NHS

Foundation Trust, United Kingdom

${ }^{*}$ Correspondence:

Vladimíra Fejfarová

vlfe@medicon.cz

Specialty section:

This article was submitted to

Clinical Diabetes,

a section of the journal

Frontiers in Endocrinology

Received: 19 July 2021 Accepted: 15 November 2021 Published: 10 December 2021

Citation:

Fejfarová V, Matuška J, Jude E, Pithová P, Flekač M, Roztočil K, Wosková V, Dubský $M$, Jirkovská $A$, Bém R, Husáková J and Lánská V

(2021) Stimulation TcPO2 Testing Improves Diagnosis of Peripheral Arteria Disease in Patients With Diabetic Foot.

Front. Endocrinol. 12:744195.

doi: 10.3389/fendo.2021.744195

\section{Stimulation TcPO2 Testing Improves Diagnosis of Peripheral Arterial Disease in Patients With Diabetic Foot}

\author{
Vladimíra Fejfarová ${ }^{*}$, Jiři Matuška ${ }^{2}$, Edward Jude ${ }^{3}$, Pavlína Pithová ${ }^{4}$, Milan Flekač ${ }^{5}$, \\ Karel Roztočil ${ }^{6}$, Veronika Wosková ${ }^{1}$, Michal Dubský ${ }^{1}$, Alexandra Jirkovská ${ }^{1}$, Robert Bém ${ }^{1}$, \\ Jitka Husáková ${ }^{1}$ and Vèra Lánská ${ }^{1}$ \\ ${ }^{1}$ Diabetes Centre, Institute for Clinical and Experimental Medicine, Prague, Czechia, ${ }^{2}$ MATMED, Vascular Outpatient Clinic, \\ Hodonín, Czechia, ${ }^{3}$ Tameside Hospital NHS Foundation Trust, Ashton-under-Lyne, United Kingdom, ${ }^{4}$ Diabetes Centre, \\ Second Faculty of Medicine, Motol Teaching Hospital, Prague, Czechia, ${ }^{5}$ First Faculty of Medicine, Charles University, \\ Prague, Czechia, ${ }^{6}$ Department of Transplant Surgery, Institute for Clinical and Experimental Medicine, Prague, Czechia
}

Background: All diagnostic procedures of peripheral arterial disease (PAD) in diabetic foot (DF) are complicated due to diabetes mellitus and its late complications. The aim of our study is to enhance diagnosis of PAD using a novel transcutaneous oximetry (TcPO2) stimulation test.

Methods: The study comprised patients with mild-to-moderate PAD(WIfl-I 1 or 2) and baseline TcPO2 values of 30-50 mmHg.TcPO2 was measured across 107 different angiosomes. Stimulation examination involved a modification of the Ratschow test. All patients underwent PAD assessment (systolic blood pressures (SBP), toe pressures (TP), the ankle-brachial indexes (ABI) and toe-brachial indexes (TBI), duplex ultrasound of circulation). Angiosomes were divided into two groups based on ultrasound findings: group $M(n=60)$ with monophasic flow; group $T(n=47)$ with triphasic flow. Large vessel parameters and TcPO2 at rest and after exercise (minimal TcPO2, changes in TcPO2 from baseline $(\Delta, \%)$, TcPO2 recovery time) measured during the stimulation test were compared between study groups.

Results: During the TcPO2 stimulation exercise test, group M exhibited significantly lower minimal TcPO2 (26.2 \pm 11.1 vs. $31.4 \pm 9.4 \mathrm{mmHg} ; \mathrm{p}<0.01)$, greater $\Delta$ and percentage decreases from resting TcPO2 ( $\mathrm{T}=0.014$ and $\mathrm{p}=0.007$, respectively) and longer TcPO2 recovery times (446 \pm 134 vs. $370 \pm 81 \mathrm{~ms} ; \mathrm{p}=0.0005$ ) compared to group T. SBPs, TPs and indexes were significantly lower in group $M$ compared to group $T$. Sensitivity and specificity of TCPO2 stimulation parameters during PAD detection increased significantly to the level of SBP, ABI, TP and TBI. 


\section{Conclusion: Compared to resting TcPO2, TcPO2 measured during stimulation improves detection of latent forms of PAD and restenosis/obliterations of previously treated arteries in diabetic foot patients.

\begin{abstract}
Clinical Trial Registration: ClinicalTrials.gov [https://register.clinicaltrials.gov/prs/app/ action/SelectProtocol?sid=S0009V7W\&selectaction=Edit\&uid $=$ U0005381\&ts $=2 \& c x=$ 3j24u2], identifier NCT04404699.
\end{abstract}

Keywords: diabetic foot, PAD - peripheral arterial disease, microcirculation, TcPO2 and TcPCO2 measurement, diagnosis

\section{BACKGROUND}

In routine foot care, peripheral arterial disease (PAD) is considered an essential diagnostic component in the treatment of diabetic foot (DF). PAD is present in about $50 \%$ of patients with $\mathrm{DF}(1,2)$. Macrovascular disease is difficult to detect in many DF patients due to the presence of diabetic sensorimotor neuropathy and medial arterial sclerosis in the lower limbs. Diabetic sensorimotor neuropathy, present in up to $90 \%$ of people with diabetes, masks symptoms of PAD due to sensory loss in the lower limbs, while medial arterial sclerosis falsely elevates arterial pressure $(3,4)$. In addition, autonomic neuropathy, which involves sympathetic denervation affecting the peripheral nerves, leads to the opening of arteriovenous shunts in the microcirculation of the lower limbs as well as alterations in pre-capillary sphincter tone. This group of conditions can result in hypoxia of peripheral tissue even without typical signs of ischaemia, such as cold feet, clinically significant changes in colour and trophic acral lesions (5). Such complications can therefore delay PAD diagnosis, in some cases until the time of DF manifestation $(6,7)$. Identifying PAD at this late stage doubles the risk of lower limb amputation in patients with DF (8).

The occurrence of PAD not only determines whether a patient is at high risk of developing potential macrovascular comorbidities $(9,10)$, but also influences DF prognosis and mortality. Therefore, appropriate diagnostic and therapeutic procedures are required if clinicians are to improve early identification of PAD and reduce the risk of amputation and mortality. Both prognosis and risk stratification of DF patients are based on WIfI classifications (11) for wound type and the presence and severity of PAD and infection. The risk of lower limb amputation increases with deeper foot ulcers and, especially, in individuals with advanced ischaemia (anklebrachial index (ABI) below 0.59 and toe pressure (TP) or transcutaneous oxygen below $39 \mathrm{~mm} \mathrm{Hg}$ ), deep infection or systemic manifestations of infection (10). DF can be stratified based on TcPO2 levels defined in the WIfI classification (11) to assist in wound healing and PAD diagnosis (12).

In this study, we present a novel diagnostic procedure for identifying micro- and macro-circulatory changes in the lower limbs. In diabetic patients, a number of metabolic changes lead to alterations in microcirculation - due to processes such as endothelial dysfunction and circulatory disturbances associated with nutritional supply to the skin - and macrocirculation secondary to accelerated atherosclerosis (9). Diabetes and its late complications such as diabetic neuropathy and mediocalcinosis often limit the accuracy of non-invasive diagnoses of micro- and macro-circulatory changes. Therefore, there is a pressing need to make diagnostic procedures more accurate. The aim of our multicentre study was to refine diagnosis of peripheral arterial disease (PAD) using a new transcutaneous oximetry (TcPO2) stimulation test in patients with DF. Combining TcPO2 measurements with a modification of the Ratschow test, our stimulation test is intended for PAD diagnosis as part of routine clinical practice. We hypothesise that our $\mathrm{TcPO} 2$ stimulation test is more accurate at screening $\mathrm{PAD}$ compared to resting $\mathrm{TcPO} 2$ measurement and reach accuracy of ABI and TBI levels routinely used in clinical practice. Provocative testing can help better differentiate the severity of perfusion abnormalities in patients with TcPO2 levels in the "grey zone". To our knowledge, this TcPO2 measurement test is the first of its kind to be assessed in patients with PAD and diabetes.

\section{METHODS}

\section{Study Subjects}

A total of 79 patients with DF were enrolled as part of the study (mean age $-66.9 \pm 10.2$ years; diabetes duration $-19.3 \pm 12.3$ years; $\mathrm{HbAlc}-63.9 \pm 17.5 \mathrm{mmol} / \mathrm{mol}$; serum creatinine - $105.4 \pm 45.6$ umol/L; haemoglobin - $133 \pm 16 \mathrm{mg} / \mathrm{dL}$; vibration perception threshold $-52 \pm 25 \mathrm{~V}$; DF in remission - 19/79 (12.7\%); chronic Charcot foot $-9 / 79$ patients $(11.4 \%)$; DF ulcers according to WIfI classification - W1fl0: 35/79 (44.3\%), W1fl1: 5/79 (6.3\%), W2fI0: 6/ 79 (7.6\%), W2fI1: 6/79 (7.6), W3fI1: 8/79 (10.1\%); all I 1-2). DF was defined as infection, ulceration or destruction of foot tissue in individuals with currently or previously diagnosed diabetes mellitus typically accompanied by neuropathy and/or PAD in the lower extremities (13). All individuals were treated in the outpatient foot clinics of three major Czech diabetes centres (Institute for Clinical and Experimental Medicine, Second Faculty of Medicine, Motol Teaching Hospital, and First Faculty of Medicine, Charles University) from January 2018 to January 2019.

Patients and DF severity were classified based on the WIfI classification. WIfI uses a combination of scores for wound (based on depth of ulcer or extent of gangrene), ischaemia (based on ankle pressure, toe pressure or TcPO2) and foot infection (based on IWGDF/IDSA criteria). These scores provide one-year risk for amputation and one-year benefit for revascularisation, stratified as very low, low, moderate or high. The WIfI classification provides a more holistic wound overview for revascularisation 
decision-making by extending the associated wound and infection criteria beyond solely perfusion pressure. Whilst WIfl has not been subject to reproducibility assessment in a DFU cohort, it boasts impressive reproducibility in a PAD setting (13). Inclusion criteria were as follows: presence of DF - defined as a foot ulcer associated with neuropathy and peripheral arterial disease in the lower extremities (13) in type 1 or type 2 diabetes mellitus; patients aged 18-70 years classified as WIfI ischaemia 1-2 (based on TcPO2 levels - mean $\mathrm{TcPO} 2=40.3 \pm 5.8 \mathrm{~mm} \mathrm{Hg}$ ) without previously diagnosed PAD or known PAD based on patient history or previous vascular reconstruction (endovascular or surgical vascular interventions). According to ESC Guidelines, TcPO2 values below $30 \mathrm{~mm} \mathrm{Hg}$ are demonstrably associated with impaired wound healing, while values above $50 \mathrm{~mm} \mathrm{Hg}$ are linked to better ulcer healing (12). Therefore, all patients were required to have baseline $\mathrm{TcPO} 2$ values of between $30-50 \mathrm{~mm} \mathrm{Hg}$ at rest.

Exclusion criteria, largely consisting of factors that affect TcPO2 measurements, were as follows: vascular intervention of the evaluated lower limb within 12 months of enrolment; factors possibly influencing oxygen saturation or lower limb movement such as patient immobility or motion impairment of the talocrural joint; vasculitis; heart failure or advanced COPD; severe anaemia (plasma haemoglobin below $8 \mathrm{~g} / \mathrm{dL}$ ); hypoperfusion due to shock or cardiac dysfunction; sepsis; massive swelling of the lower limbs of various aetiology (including lymphedoema); active Charcot osteoarthropathy; severe autonomic neuropathy causing orthostatic hypotension, sinus tachycardia or manifesting in other organ systems; critical limb ischaemia of WIfI class ischaemia 3; lower limb claudication below 200m; ulcers of venous insufficiency or combined aetiology; severe diabetic kidney disease (CKD stage 4 or 5) (14).

Patients were treated according to the IWGDF Guidelines on the Prevention and Management of Diabetic Foot Disease, devised to improve diabetes control and detect and treat foot infection and biomechanical changes (15).

Prior to enrolment in the study, each patient signed an informed consent form approved by the local ethics committees of the Institute for Clinical and Experimental Medicine and Thomayer Hospital.

\section{Assessment of Lower Limb Vascular Status \\ Large Vessels}

Assessment of peripheral arterial circulation consisted of foot pulse measurement and ultrasound of the peripheral arteries (16). Systolic blood pressure (SBP) in the peripheral arteries (DPA, Dorsalis pedis artery; PTA, posterior tibial artery) and digital arteries (TP, Toe pressure) was measured using a handheld Doppler ultrasound device with an $8 \mathrm{MHz}$ probe (EDAN SD3 Vascular, DOTmed, NY, USA). The same technique was used to evaluate ankle-brachial indexes (ABI) and toe-brachial indexes (TBI).

Given the frequent inaccuracies associated with ABI, we used colour-coded duplex utrasound (DUS) as the gold standard for $\mathrm{PAD}$ detection. DUS was used to assess morphology and flow in the peripheral arteries (4-8 MHz probe, factory default setting, LOGIQ P7, GE HealthCare, USA). Pulse wave correction was set at 70 degrees as standard followed by appropriate adaptation of pulse repetition frequency. Monophasic waves were used to determine the presence of haemodynamically significant stenosis or obliteration with collateralisation. Those arterial lesions modifying pulse waveforms are considered to be clinically hemodynamic significant to reduce dramatically peripheral perfusion.

\section{TcPO2}

Transcutaneous oxygen pressure (TcPO2) was measured on the Clark electrode, a method used to electrochemically assess partial pressure of oxygen on the surface of the skin (17). A standard probe, consisting of a small chamber containing silver and platinum electrodes with an oxygen-permeable membrane, was heated to $42-45^{\circ} \mathrm{C}$ for arterialised cutaneous flow, thus increasing oxygen diffusion through the skin via local vasodilatation. The results obtained were automatically recalculated to $37^{\circ} \mathrm{C}(17)$. Prior to measurement, subjects were required to rest in a quiet room maintained at a temperature of $20^{\circ} \mathrm{C}$ and to abstain from the use of tobacco and alcohol. $\mathrm{TcPO}_{2}$ was subsequently measured in respective angiosomes (Figure 1) $(18,19)$.

All centres used the same device for TcPO2 measurement (TINA, Radiometer, Copenhagen). Since photoelectric probes used by other devices result in approximately $15 \mathrm{~mm} \mathrm{Hg}$-higher values when measured at rest, electrochemical methods were applied as standard (20).

\section{TcPO2 Stimulation Test}

After TcPO2 measurement of the respective angiosomes (probes placed in angiosomes supplied by DPA and/or PTA) (Figure 1) and once a steady resting state was achieved, the modified Ratschow stimulation test was performed $(21,22)$. The standardised Ratschow test consists of elevating both lower extremities to approximately 50 degrees for 30 seconds. At this stage, a change in skin colour is considered specific to ischaemia. While in the elevated position, the subject continues with dorsal and plantar flexions of the talocrural joints for 90 seconds. Provocation of pain or discoloration at this stage may be a sign of ischaemia. The subject then returns the lower legs to a horizontal position. At this point, physiological changes in skin colour are again monitored. Although once widely used in Western and Central Europe, the technique has now largely become obsolete due to the increased availability of Doppler and duplex ultrasound devices. Active dorsal and plantar flexions of the talocrural joints are mostly constant, having almost no influence on active long-term contractions of the thigh muscles. Moreover, the dependent position the patient returns to remains unchanged.

Our modification of the Ratschow test involves elevating the lower limbs (30 $\mathrm{cm}$ above the bed) followed by rhythmic maximal plantar flexion and extension of the talocrural joints for 2 minutes (Figure 2).

Since active elevation of the lower extremities can be problematic in subjects with joint, vertebral column or muscle impairment, we used a cushion with a predefined height for mechanical support (Figure 2). TcPO2 was measured continuously throughout. The lower limbs were returned to the horizontal position at the end of the exercise before continuing with $\mathrm{TcPO} 2$ measurement. Considering the novel nature of the test and based on our clinical 


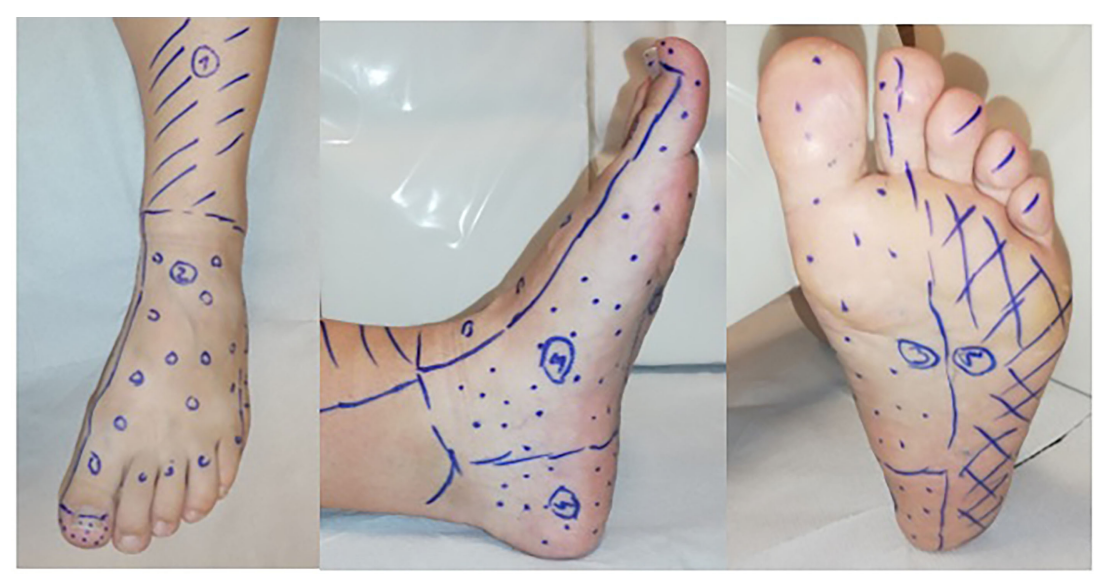

FIGURE 1 | Distribution of angiosomes in the lower limb. 1- Angiosomes supplied by: anterior tibial artery (ATA); 2 - dorsalis pedis artery (DPA); 3 -medial plantar artery; 4 - calcaneal branch of the posterior tibial artery (PTA) (angiosomes 3 and 4 are supplied by the PTA); 5 - lateral plantar artery.

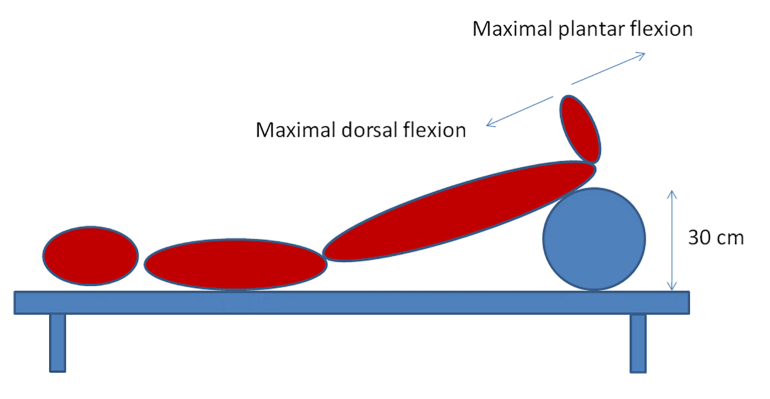

FIGURE 2 | Modified Ratschow test.

experience, we extended the post-exercise recovery window to at least 8-10 minutes to ensure $\mathrm{TcPO} 2$ normalisation. This stimulation test is not time-consuming and lasts approximately 20-25 minutes. It could supplement the standard TcPO2 measurement.

\section{Evaluation of Large Vessels and TcPO2 Parameters}

We assessed 107 angiosomes in 79 patients, dividing them (angiosomes) according to flow type as detected by DUS. In a small minority of patients ( $8.9 \%$ of patients - 7/79), both lower limbs were examined. However, in the majority of patients, only the affected lower limb was examined. We examined 1, maximum 2 angiosomes based on DPA and/or PTA distribution. Angiosomes were divided into two groups: group $M(n=60)$ with verified monophasic flow or obliteration; group $T(n=47)$ with verified triphasic flow. Flow in PTA was detected by the probe located behind the ankle and DPA by probe placed proximally on the instep of the foot. Five angiosomes were excluded from the overall statistical evaluation after DUS detected biphasic arterial flow. All patients with verified biphasic flow were excluded from the overall statistical evaluation.
We further compared macrocirculation parameters (systolic pressure in DPA and PTA) and Doppler indexes with the ABIs of DPA and PTA, toe pressure (TP) and TBIs between study groups. The following parameters were also compared: resting TcPO2; minimal TcPO2 (23) detected during the stimulation test; delta value $(\Delta)$ - defined as resting TcPO2 minus minimal TcPO2 during the stimulation test; percentage decrease in $\mathrm{TcPO} 2$ during the stimulation test; $\mathrm{TcPO} 2$ recovery time before returning to resting values (Figure 3 ). We also compared correlations of all $\mathrm{TcPO} 2$ values to macrocirculation parameters, including sensitivity and specificity, in relation to the presence of PAD based on monophasic arterial flow in the respective artery.

\section{Statistical Analysis}

The Shapiro-Wilk test was used for Gaussian distribution. Gaussian variables were assessed using the t-test. For variables differing from Gaussian distribution, the Mann-Whitney test was applied. For discrete variables, the $\chi^{2}$-test of independence with contingency tables were used. To measure relations between variables, the correlation coefficient was used. Sensitivity and specificity were demonstrated using ROC curves. Youden's J-index was used to determine the optimal cut-point based on ROC analysis. A twosided p-value of less then 0.05 was considered statistically significant. All calculations were carried out using JMP 11 statistical software (2013) (SAS Institute, Cary, USA).

\section{RESULTS}

Study groups differed significantly with regard to incidence of previously diagnosed PAD (84\% of patients in group M vs. $43 \%$ of patients in group $\mathrm{T} ; \mathrm{p}<0.0001)$ and the number of patients to have undergone revascularisation procedures $(68.4 \%$ of patients in group $\mathrm{M}$ vs. $26.2 \%$ in group $\mathrm{T} ; \mathrm{p}<0.0001)$. The other baseline 
characteristics were not found to be significantly different (Table 1).

During the TcPO2 stimulation test, we observed a significant decrease in TcPO2 in both study groups (from 40.6 to $26.2 \mathrm{~mm}$ $\mathrm{Hg}$ in group $\mathrm{M}$ and from 41.4 to $31.4 \mathrm{~mm} \mathrm{Hg}$ in group $\mathrm{T}$; both $\mathrm{p}<0.0001$ ) (Table 2). However, the decrease of TcPO2 $(\Delta)$ was significantly higher in group $\mathrm{M}$ compared to group $\mathrm{T}(-14.4 \pm 9.6$ vs. $-9.88 \pm 8.5 \mathrm{~mm} \mathrm{Hg} ; \mathrm{p}=0.014)$. There was also a significant percentage decrease of TcPO2 in group $\mathrm{M}$ compared to group $\mathrm{T}$ during the stimulation test $(-36 \pm 25$ vs. $-24 \pm 21 \%$; $\mathrm{p}=0.007)$. TcPO2 recovery time was also different, with recovery-tobaseline much higher in group $\mathrm{M}(446 \pm 134$ vs. $370 \pm 81$ seconds; $\mathrm{p}=0.0005$ ) (Table 2).

Both systolic ankle pressure, TP and their respective indexes (ABI-DPA, ABI-PTA and TBI) were significantly lower in group $\mathrm{M}$ compared to group $\mathrm{T}$ (Table 2 ). We found positive correlations of ABI-DPA, ABI-PTA, TP and TBI. While we observed minimal TcPO2 values achieved during exercise (Table 2), we found negative correlations of TP and TBI to $\Delta$ $\mathrm{TcPO} 2$, the percentage decrease of $\mathrm{TcPO} 2$, and $\mathrm{TcPO} 2$ recovery time (Table 3).

Sensitivity and specificity of macrocirculation parameters (systolic ankle pressure, TP and their indexes ABI-DPA, ABIPTA and TBI) in relation to monophasic flow ranged between $69-78 \%$ and $64-78 \%$, respectively (Table 4 and Figure 4). For individual macrocirculation parameters considered decisive according to WIfI classification such as an $\mathrm{ABI} \leq 0.4$, sensitivity was below $10 \%$ and $8 \%$, with specificity at $100 \%$ and
$100 \%$, respectively; for an $\mathrm{ABI} \leq 0.8$, sensitivity was $35.1 \%$ and $42.9 \%$, with specificity at $97.73 \%$ and $77.1 \%$, respectively. Similarly, TP $\leq 30 \mathrm{~mm} \mathrm{Hg}$ sensitivity was $10.3 \%$ and specificity $97.2 \%$, while $\mathrm{TP} \leq 60 \mathrm{~mm} \mathrm{Hg}$ sensitivity was $69.2 \%$ and specificity $77.8 \%$ (Table 4 and Figure 4). The sensitivity and specificity of resting $\mathrm{TcPO} 2(<39 \mathrm{~mm} \mathrm{Hg})$ in relation to monophasic flow was $48 \%$ and $57 \%$, respectively (Table 5). After stimulation, however, the informative value of the TcPO2 parameters measured $(\Delta \mathrm{TcPO} 2$ and the percentage decrease of TcPO2) increased dramatically, with sensitivity reaching $60-65 \%$ and specificity 62-68\% (Table 5 and Figure 5). During the stimulation test, the highest sensitivity and specificity achieved was for TcPO2 recovery time (above 360 s; sensitivity at $73.3 \%$ and specificity at 68.1\%) (Figure 5).

\section{DISCUSSION}

In routine podiatry practice, $\mathrm{TcPO} 2$ is used to determine the state of microcirculation and estimate the probability of wound healing (24). The literature suggests that TcPO2 has a reliable predictive value in the prognosis of diabetic foot ulcer (DFU) healing (with sensitivity at $72 \%$ and specificity at $86 \%$ ) (25). There is a higher probability of wound healing in patients with TcPO2 values above $40 \mathrm{~mm} \mathrm{Hg}$ (26). However, in many cases, TcPO2 does not reveal the true state of macrocirculation. Recently, TcPO2 was added to the WIfI classification system. Non-ischaemia is defined as a TcPO2 value above $60 \mathrm{~mm} \mathrm{Hg}$,

TABLE 1 | Comparison of basal characteristics between study groups.

\begin{tabular}{|c|c|c|c|}
\hline Evaluated parameters & Group M $(n=60)$ & Group T $(n=47)$ & p-value \\
\hline Age (years) & $68.6 \pm 9.9$ & $66.2 \pm 9.05$ & NS \\
\hline Diabetes duration (years) & $19.03 \pm 12.6$ & $19.13 \pm 11.4$ & NS \\
\hline $\mathrm{HbA1c}(\mathrm{mmol} / \mathrm{mol})$ & $61.7 \pm 17.2$ & $65.9 \pm 14.4$ & NS \\
\hline Creatinine serum level (umol/l) & $107.8 \pm 36$ & $100.2 \pm 47.5$ & NS \\
\hline $\mathrm{Hb}(\mathrm{mg} / \mathrm{dl})$ & $132.8 \pm 17.2$ & $131.6 \pm 13.7$ & NS \\
\hline Biothesiometer ( $)$ & $48 \pm 20.4$ & $55.3 \pm 27.2$ & NS \\
\hline
\end{tabular}

NS, non significant.

TABLE 2 | Comparison of TcPO2 parameters detected during stimulation test and large vessel parameters between study groups.

\begin{tabular}{|c|c|c|c|}
\hline Evaluated parameters & Group M $(n=60)$ & Group T $(n=47)$ & p-value \\
\hline Resting TcPO2 (mm Hg) & $40.6 \pm 5.9$ & $41.4 \pm 5.5$ & NS \\
\hline Minimal TcPO2 detected during stimulation test $(\mathrm{mm} \mathrm{Hg})$ & $26.2 \pm 11.1$ & $31.4 \pm 9.4$ & $p=0.01$ \\
\hline TcPO2 after stimulation test & $40.3 \pm 8.4$ & $41.8 \pm 6.7$ & NS \\
\hline$\Delta$ of $\mathrm{TCPO} 2$ (= resting minus minimal TcPO2) & $14.4 \pm 9.6$ & $9.98 \pm 8.5$ & $p=0.014$ \\
\hline Percentage of TcPO2 decrease (\%) & $36 \pm 25$ & $24 \pm 21$ & $p=0.007$ \\
\hline Duration of TcPO2 recovery $(\mathrm{s})$ & $446 \pm 134$ & $370 \pm 81$ & $p=0.0005$ \\
\hline Systolic blood pressure in DPA (mm Hg) & $149 \pm 62$ & $183 \pm 44$ & $p=0.007$ \\
\hline Systolic blood pressure in PTA (mm Hg) & $138 \pm 68$ & $181 \pm 50$ & $p=0.001$ \\
\hline $\mathrm{ABI}-\mathrm{DPA}$ & $0.93 \pm 0.4$ & $1.2 \pm 0.3$ & $p<0.0001$ \\
\hline ABI-PTA & $0.9 \pm 0.4$ & $1.2 \pm 0.3$ & $p=0.0004$ \\
\hline TP (mm Hg) & $59.9 \pm 19.9$ & $89.5 \pm 30.8$ & $\mathrm{p}<0.0001$ \\
\hline $\mathrm{TBI}$ & $0.39 \pm 0.11$ & $0.62 \pm 0.21$ & $p<0.0001$ \\
\hline
\end{tabular}

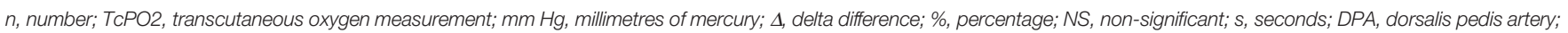
PTA, posterior tibial artery; ABI, ankle-brachial index; TP, toe pressure; TBI, toe-brachial index. 
TABLE 3 | Correlation between large-vessel and TCPO2 stimulation parameters.

\begin{tabular}{|c|c|c|c|}
\hline Large-vessel parameters & TcPO2 parameters & $\mathbf{r}$ & p-value \\
\hline \multirow[t]{4}{*}{ Systolic blood pressure in DPA (mm Hg) } & Minimal TcPO2 & 0.0746 & NS \\
\hline & $\Delta$ of TcPO2 & -0.05360 & NS \\
\hline & $\%$ decrease of TcPO2 & -0.0678 & NS \\
\hline & Duration of TcPO2 recovery & -0.2045 & 0.0784 \\
\hline \multirow[t]{4}{*}{ Systolic blood pressure in PTA (mm Hg) } & Minimal TcPO2 & 0.0916 & NS \\
\hline & $\Delta$ of $\mathrm{TcPO} 2$ & -0.0446 & NS \\
\hline & $\%$ decrease of $\mathrm{TcPO} 2$ & -0.0703 & NS \\
\hline & Duration of TcPO2 recovery & -0.1602 & NS \\
\hline \multirow[t]{4}{*}{ ABI-DPA } & Minimal TcPO2 & 0.2634 & 0.0175 \\
\hline & $\Delta$ of $\mathrm{TcPO} 2$ & -0.1758 & NS \\
\hline & $\%$ decrease of $\mathrm{TcPO} 2$ & -0.2148 & 0.0542 \\
\hline & Duration of TcPO2 recovery & -0.2096 & 0.0604 \\
\hline \multirow[t]{4}{*}{ ABI-PTA } & Minimal TcPO2 values & 0.2208 & 0.0297 \\
\hline & $\Delta$ of TcPO2 & -0.1345 & NS \\
\hline & $\%$ decrease of TcPO2 & -0.1758 & 0.0850 \\
\hline & Duration of TcPO2 recovery & -0.2303 & 0.0233 \\
\hline \multirow[t]{4}{*}{ TP (mm Hg) } & Minimal TcPO2 & 0.2864 & 0.0127 \\
\hline & $\Delta$ of $\mathrm{TcPO} 2$ & -0.3655 & 0.0013 \\
\hline & $\%$ decrease of TcPO2 & -0.3619 & 0.0014 \\
\hline & Duration of TcPO2 recovery & -0.4113 & 0.0002 \\
\hline \multirow[t]{4}{*}{$\mathrm{TBI}$} & Minimal TcPO2 & 0.3533 & 0.0017 \\
\hline & $\Delta$ of $\mathrm{TcPO} 2$ & -0.4051 & 0.0003 \\
\hline & $\%$ decrease of TcPO2 & -0.4141 & 0.0002 \\
\hline & Duration of TcPO2 recovery & -0.4747 & $<0.0001$ \\
\hline
\end{tabular}

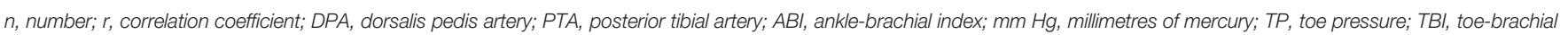
index; TCPO2, transcutaneous oxygen measurement; $\mathrm{mm} \mathrm{Hg}$, millimetres of mercury; $\Delta$, delta difference; \%, percentage; NS, non-significant.

with mild ischaemia between 40 and $59 \mathrm{~mm} \mathrm{Hg}$. Patients with TcPO2 values between 30 and $39 \mathrm{~mm} \mathrm{Hg}$ typically suffer from moderate PAD and those with TcPO2 $<30 \mathrm{~mm} \mathrm{Hg}$ from critical limb-threatening ischaemia. The European Society for Vascular Surgery (ESVS) Guidelines define the impairment of circulation status as a TcPO2 value below $40 \mathrm{~mm} \mathrm{Hg}$ and state that alteration of large vessels is frequently detected in patients with TcPO2 values below $40 \mathrm{~mm} \mathrm{Hg}$ (10). Clinically, however, healing processes can alter in patients with $\mathrm{TcPO} 2$ values above 30 or $40 \mathrm{~mm} \mathrm{Hg}$. Therefore, to establish the presence of PAD, such patients should either undergo non-invasive examination or treatment involving the modification of existing noninvasive methods.

There are notable limitations to the use of standard noninvasive $\mathrm{PAD}$ diagnostics in routine clinical practice. Many patients with DF do not display classic PAD symptoms (coldness/acral lividosis, colour changes, claudication, resting ischaemic pain or weak/absent peripheral pulsation), most often due to distal sensorimotor neuropathy $(2,27)$. Doppler examination of $\mathrm{ABI}$ and $\mathrm{TP}$ is often inapplicable in cases of medial sclerosis (10), skin lesions that contraindicate the use of instruments, and the absence of toes. Also, ultrasound examination of lower limb arteries can be complicated by the presence of arterial calcifications, especially in distal vessels (28).

TcPO2 is a well-established method for assessing tissue perfusion/oxygenation. The use of other methods such as laser Doppler and laser speckle imaging are less common. TcPO2 devices are relatively inexpensive and widely used in diabetic, vascular and surgery clinics throughout the Czech Republic. Therefore, any potential improvements in examination protocols are likely to be easily implemented. According to recent guidelines, arterial flow should be examined, especially in patients with diabetes, using several non-invasive methods or by modifying existing procedures to increase the predictive value of PAD (29). However, there are occasional discrepancies between individual diagnostic findings. For instance, although high TcPO2 levels typically indicate a satisfactory state of microcirculation, some DUS results clearly prove severe atherosclerotic involvement in macrocirculation. In this study, we used a modified $\mathrm{TcPO} 2$ procedure commonly used in podiatry practice to refine $\mathrm{PAD}$ diagnosis (including latent $\mathrm{PAD}$ and restenosis/obliteration following revascularisation) in patients with DF. In addition to standard TcPO2 examination (30), we used a modified Ratschow stimulation test (31), which augments $\mathrm{TcPO} 2$ measurements through exercise, similar to other methods described by Audonnet (32), Abraham (33) and Kovacseva (34). Previous studies have shown that exercise TcPO2 stimulation tests may be better at detecting proximal ischaemia (32) and peripheral arterial disease (34). For the stimulation tests performed in the above studies, the treadmill was used as the standard exercise equipment. However, this mode of exercise is not recommended in DF patients who (i) have claudication associated with peripheral sensorimotor neuropathy, (ii) are required to off-load affected limbs, (iii) have been previously amputated, or (iv) are prone to physical instability. To provide a stimulus that would not load the lower extremities, we performed a modified Ratschow test. To date, this type of TcPO2 stimulation test has yet to be performed in patients with suspected $\mathrm{PAD}$, diabetes or DF where the localisation of lesions is likely to be peripheral. 
TABLE 4 | Sensitivity and specificity of individual macrovascular assessment in relation to monophasic arterial flow supplying the relevant angiosome.

\begin{tabular}{|c|c|c|c|c|c|c|c|c|}
\hline $\begin{array}{l}\text { Evaluated } \\
\text { parameters } \\
\text { Determined } \\
\text { values }\end{array}$ & $\begin{array}{c}\text { SBP DPA - sensitivity } \\
(95 \% \mathrm{Cl})\end{array}$ & $\begin{array}{c}\text { SBP DPA - specificity } \\
(95 \% \mathrm{Cl})\end{array}$ & $\begin{array}{l}\text { Evaluated } \\
\text { parameter }\end{array}$ & $\begin{array}{c}\text { SBP PTA - } \\
\text { sensitivity }(95 \% \mathrm{Cl})\end{array}$ & $\begin{array}{c}\text { SBP PTA - specificity } \\
(95 \% \mathrm{Cl})\end{array}$ & $\begin{array}{l}\text { Evaluated } \\
\text { parameter }\end{array}$ & $\begin{array}{c}\text { SBP TP - } \\
\text { sensitivity (95\% } \\
\text { CI) }\end{array}$ & $\begin{array}{c}\text { SBP TP - specificity } \\
(95 \% \mathrm{Cl})\end{array}$ \\
\hline$<20 \mathrm{~mm} \mathrm{Hg}$ & $0.0 \%(0.0-8.8)$ & $100 \%(90.0-100)$ & $<0 \mathrm{~mm} \mathrm{Hg}$ & $0 \%(0-6.7)$ & $100 \%(91.0-100)$ & $<15 \mathrm{~mm} \mathrm{Hg}$ & $0 \%(0-9.0)$ & $100 \%(90.3-100)$ \\
\hline$\leq 75$ & $7.5 \%(1.6-20.4)$ & $100 \%(90.0-100)$ & $\leq 20$ & $9.43 \%(3.1-20.7)$ & $100 \%(91.0-100)$ & $\leq 20$ & $2.56 \%(0.06-13.5)$ & $97.22 \%(85.5-99.9)$ \\
\hline$\leq 80$ & $10 \%(2.8-23.7)$ & $97.14 \%(85.1-99.9)$ & $\leq 70$ & $11.32 \%(4.3-23.0)$ & $97.44 \%$ (86.5-99.9) & $\leq \mathbf{3 0}$ & $10.26 \%(2.9-24.2)$ & $97.22 \%(85.5-99.9)$ \\
\hline$\leq 100$ & $27.5 \%(14.6-43.9)$ & $97.14 \%(85.1-99.9)$ & $\leq 90$ & $20.75 \%(10.8-34.1)$ & $97.44 \%$ (86.5-99.9) & $\leq 40$ & $12.82 \%(4.3-27.4)$ & $88.89 \%(73.9-96.9)$ \\
\hline$\leq 110$ & $27.5 \%$ (14.6-43.9) & $94.29 \%(80.8-99.3)$ & $\leq 100$ & $24.53 \%(13.8-38.3)$ & $89.74 \%(75.8-97.1)$ & $\leq 47$ & $25.64 \%(13-42.1)$ & $88.89 \%(73.9-96.9)$ \\
\hline$\leq 116$ & $32.5 \%(18.6-49.1)$ & $94.29 \%(80.8-99.3)$ & $\leq 104$ & $28.3 \%(16.8-42.3)$ & $89.74 \%$ (75.8-97.1) & $\leq 50$ & $33.33 \%(19.1-50.2)$ & 83.33\% (67.2-93.6) \\
\hline$\leq 120$ & $35 \%(20.6-51.7)$ & $88.57 \%$ (73.3-96.8) & $\leq 116$ & $41.51 \%(28.1-55.9)$ & $82.05 \%(66.5-92.5)$ & $\leq 55$ & $46.15 \%(30.1-62.8)$ & $83.33 \%(67.2-93.6)$ \\
\hline$\leq 130$ & $47.5 \%(31.5-63.9)$ & $88.57 \%(73.3-96.8)$ & $\leq 130$ & $56.6 \%(42.3-70.2)$ & $74.36 \%(57.9-87.0)$ & $\leq 60$ & $69.23 \%(52.4-83)$ & $77.78 \%(60.8-89.9)$ \\
\hline$\leq 140$ & $55 \%(38.5-70.7)$ & $80 \%(63.1-91.6)$ & $\leq 140$ & $56.6 \%$ (42.3-70.2) & $71.79 \%(55.1-85.0)$ & $\leq 64$ & $69.23 \%(52.4-83)$ & $75 \%(57.8-87.9)$ \\
\hline$\leq 142$ & $57.5 \%(40.9-73.0)$ & $80 \%(63.1-91.6)$ & $\leq 142$ & $58.49 \%(44.1-71.9)$ & $71.79 \%(55.1-85.0)$ & $\leq 70$ & $74.36 \%(57.9-87.0)$ & $63.89 \%(46.2-79.2)$ \\
\hline$\leq 150$ & $62.5 \%(45.8-77.3)$ & $74.29 \%(56.7-87.5)$ & $\leq 150$ & $62.26 \%(47.9-75.2)$ & $69.23 \%(52.4-83.0)$ & $\leq 75$ & $76.92 \%(60.7-88.9)$ & $63.89 \%(46.2-79.2)$ \\
\hline$\leq 156$ & $65 \%(48.3-79.4)$ & $74.29 \%(56.7-87.5)$ & $\leq 160$ & $64.15 \%(49.8-76.9)$ & $69.23 \%(52.4-83.0)$ & $\leq 80$ & $87.18 \%(72.6-95.7)$ & $55.56 \%(38.1-72.1)$ \\
\hline$\leq 160$ & $70 \%(53.5-83.4)$ & $71.43 \%(53.7-85.4)$ & $\leq 170$ & $69.81 \%(55.7-81.7)$ & $64.1 \%(47.2-78.8)$ & $\leq 85$ & $92.31 \%(79.1-98.4)$ & $52.78 \%(35.5-69.6)$ \\
\hline$\leq 180$ & $70 \%(53.5-83.4)$ & $54.29 \%(36.6-71.2)$ & $\leq 180$ & $73.58 \%(59.7-84.7)$ & $43.59 \%(27.8-60.4)$ & $\leq 90$ & $94.87 \%(82.7-99.4)$ & $33.33 \%(18.6-51)$ \\
\hline$\leq 190$ & $75 \%(58.8-87.3)$ & $48.57 \%(31.4-66)$ & $\leq 190$ & $75.47 \%(61.7-86.2)$ & $38.46 \%(23.4-55.4)$ & $\leq 100$ & $97.44 \%(86.5-99.9)$ & $22.22 \%(10.1-39.2)$ \\
\hline$\leq 200$ & $75 \%(58.8-87.3)$ & $37.14 \%(21.5-55.1)$ & $\leq \mathbf{2 0 0}$ & $77.36 \%(63.8-87.7)$ & $35.9 \%(21.2-52.8)$ & $\leq 110$ & $100 \%(91-100)$ & $19.44 \%(8.2-36)$ \\
\hline \multirow[t]{3}{*}{$\leq 220$} & $85 \%(70.2-94.3)$ & $11.43 \%(3.2-26.7)$ & $\leq 220$ & $92.45 \%(81.8-97.9)$ & $15.38 \%(5.9-30.5)$ & $\leq 170$ & $100 \%(91-100)$ & $0 \%(0-9.7)$ \\
\hline & $\begin{array}{l}\text { Significance } \\
p=0.0032\end{array}$ & Youden's $\mathrm{J}$ index 0.414 & & $\begin{array}{l}\text { Significance } \\
p=0.0032\end{array}$ & Youden's J index 0.3391 & & $\begin{array}{l}\text { Significance } \\
p<0.0001\end{array}$ & Youden's $\mathrm{J}$ index 0.4701 \\
\hline & AUC 0.687 & $\begin{array}{l}95 \% \text { confidence interval } \\
0.569 \text { to } 0.789\end{array}$ & & AUC 0.667 & $\begin{array}{l}95 \% \text { confidence interval } \\
0.561 \text { to } 0.762\end{array}$ & & AUC 0.762 & $\begin{array}{l}95 \% \text { confidence Interval } \\
0.649 \text { to } 0.853\end{array}$ \\
\hline $\begin{array}{l}\text { Evaluated parameters } \\
\text { Determined } \\
\text { values }\end{array}$ & $\begin{array}{l}\text { ABI DPA - } \\
\text { sensitivity }(95 \% \mathrm{Cl})\end{array}$ & $\begin{array}{l}\text { ABI DPA - specificity } \\
(95 \% \mathrm{Cl})\end{array}$ & $\begin{array}{l}\text { Evaluated } \\
\text { parameter }\end{array}$ & $\begin{array}{l}\text { ABI PTA- } \\
\text { sensitivity (95\% } \\
\text { Cl) }\end{array}$ & $\begin{array}{l}\text { ABI PTA- specificity } \\
(95 \% \mathrm{Cl})\end{array}$ & $\begin{array}{l}\text { Evaluated } \\
\text { parameter }\end{array}$ & $\begin{array}{l}\text { TBI - sensitivity } \\
(95 \% \mathrm{Cl})\end{array}$ & $\begin{array}{l}\text { TBI - Specificity ( } 95 \% \\
\text { CI) }\end{array}$ \\
\hline$<0.18$ & $0.0 \%(0.0-9.5)$ & $100 \%(92-100)$ & $<0$ & $0.0 \%(0.0-7.3)$ & $100 \%(92.6-100)$ & $<0.13$ & $0.0 \%(0.0-8.8)$ & $100 \%(90.3-100)$ \\
\hline$\leq 0.58$ & $8.11 \%(1.7-21.9)$ & $100 \%(92-100)$ & $\leq 0.47$ & $10.2 \%(3.4-22.2)$ & $100 \%(92.6-100)$ & $\leq 0.23$ & $10 \%(2.8-23.7)$ & $97.2 \%(85.5-99.9)$ \\
\hline$\leq 0.62$ & $8.11 \%(1.7-21.9)$ & $97.73 \%(88-99.9)$ & $\leq 0.54$ & $12.24 \%(4.6-24.8)$ & $97.92 \%(88.9-99.9)$ & $\leq 0.31$ & $30 \%(16.6-46.5)$ & $91.67 \%(77.5-98.2)$ \\
\hline$\leq 0.82$ & $35.14 \%(20.2-52.5)$ & $97.73 \%(88-99.9)$ & $\leq 0.62$ & $16.33 \%(7.3-29.7)$ & $95.83 \%$ (85.7-99.5) & $\leq 0.34$ & $40 \%(24.9-56.7)$ & $86.11 \%(70.5-95.3)$ \\
\hline$\leq 0.83$ & $37.84 \%$ (22.5-55.2) & $93.18 \%(81.3-98.6)$ & $\leq 0.7$ & $28.57 \%(16.6-43.3)$ & $89.58 \%$ (77.3-96.5) & $\leq 0.4$ & $52.5 \%(36.1-68.5)$ & $77.78 \%(60.8-89.9)$ \\
\hline$\leq 0.9$ & $40.54 \%(24.8-57.9)$ & $90.91 \%(78.3-97.5)$ & $\leq 0.8$ & $42.86 \%(28.8-57.8)$ & $77.08 \%(62.7-88)$ & $\leq 0.43$ & $72.5 \%(56.1-85.4)$ & $75 \%(57.8-87.9)$ \\
\hline$\leq 0.933$ & $48.65 \%(31.9-65.6)$ & $90.91 \%(78.3-97.5)$ & $\leq 0.9$ & $55.1 \%(40.2-69.3)$ & $70.83 \%$ (55.9-83) & $\leq 0.47$ & $77.5 \%(61.5-89.2)$ & $75 \%(57.8-87.9)$ \\
\hline$\leq 0.96$ & $48.65 \%$ (31.9-65.6) & $86.36 \%$ (72.6-94.8) & $\leq 1.01$ & $69.39 \%(54.6-81.7)$ & $68.75 \%(53.7-81.3)$ & $\leq 0.5$ & $85 \%(70.2-94.3)$ & $58.33 \%(40.8-74.5)$ \\
\hline$\leq 1$ & $75.68 \%$ (58.8-88.2) & $68.18 \%(52.4-81.4)$ & $\leq 1.06$ & $73.47 \%(58.9-85.1)$ & $62.5 \%(47.4-76)$ & $\leq 0.53$ & $92.5 \%$ (79.6-98.4) & $55.56 \%$ (38.1-72.1) \\
\hline$\leq 1.05$ & $78.38 \%(61.8-90.2)$ & $63.64 \%(47.8-77.6)$ & $\leq 1.17$ & $75.51 \%(61.1-86.7)$ & $47.92 \%(33.3-62.8)$ & $\leq 0.57$ & $95 \%(83.1-99.4)$ & $52.78 \%(35.5-69.6)$ \\
\hline$\leq 1.1$ & $78.38 \%$ (61.8-90.2) & $56.82 \%(41-71.7)$ & $\leq 1.22$ & $81.63 \%(68-91.2)$ & $45.83 \%(31.4-60.8)$ & $\leq 0.6$ & $97.5 \%(86.8-99.9)$ & $47.22 \%(30.4-64.5)$ \\
\hline$\leq 1.16$ & $83.78 \%(68-93.8)$ & $52.27 \%(36.7-67.5)$ & $\leq 1.26$ & $85.71 \%(72.8-94.1)$ & $41.67 \%(27.6-56.8)$ & $\leq 1.13$ & $100 \%(91.2-100)$ & $0 \%(0-9.7)$ \\
\hline$\leq 1.3$ & $86.49 \%$ (71.2-95.5) & $31.82 \%(18.6-47.6)$ & $\leq 1.4$ & $85.71 \%(72.8-94.1)$ & $20.83 \%(10.5-35)$ & & & \\
\hline$\leq 1.38$ & $89.19 \%(74.6-97)$ & $22.73 \%(11.5-37.8)$ & $\leq 1.52$ & $93.88 \%(83.1-98.7)$ & $8.33 \%(2.3-20)$ & & & \\
\hline \multirow[t]{3}{*}{$\leq 1.52$} & $97.3 \%(85.8-99.9)$ & $6.82 \%(1.4-18.7)$ & & & & & & \\
\hline & $\begin{array}{l}\text { Significance } \\
p<0.0001\end{array}$ & Youden's $\mathrm{J}$ index 0.4386 & & $\begin{array}{l}\text { Significance } \\
p=0.0009\end{array}$ & Youden's $\mathrm{J}$ index 0.3814 & & $\begin{array}{l}\text { Significance } \\
p<0.0001\end{array}$ & Youden's $\mathrm{J}$ index 0.5250 \\
\hline & AUC 0.768 & $\begin{array}{l}95 \% \text { confidence interval } \\
0.660 \text { to } 0.854\end{array}$ & & AUC 0.683 & $\begin{array}{l}95 \% \text { confidence interval } \\
0.581 \text { to } 0.774\end{array}$ & & AUC 0.798 & $\begin{array}{l}95 \% \text { confidence interval } \\
0.690 \text { to } 0.881\end{array}$ \\
\hline
\end{tabular}

SBP, systolic blood pressure; DPA, dorsalis pedis artery; PTA, posterior tibial artery; TP, toe pressure; p, significance; Cl, confidence interval, mm Hg, millimetres of mercury; AUC, area under the ROC curve; ABI, ankle-brachial index; TBI, toebrachial index; $p$, significance; the highest sensitivity and specificity for individual measurements are highlighted in bold. 


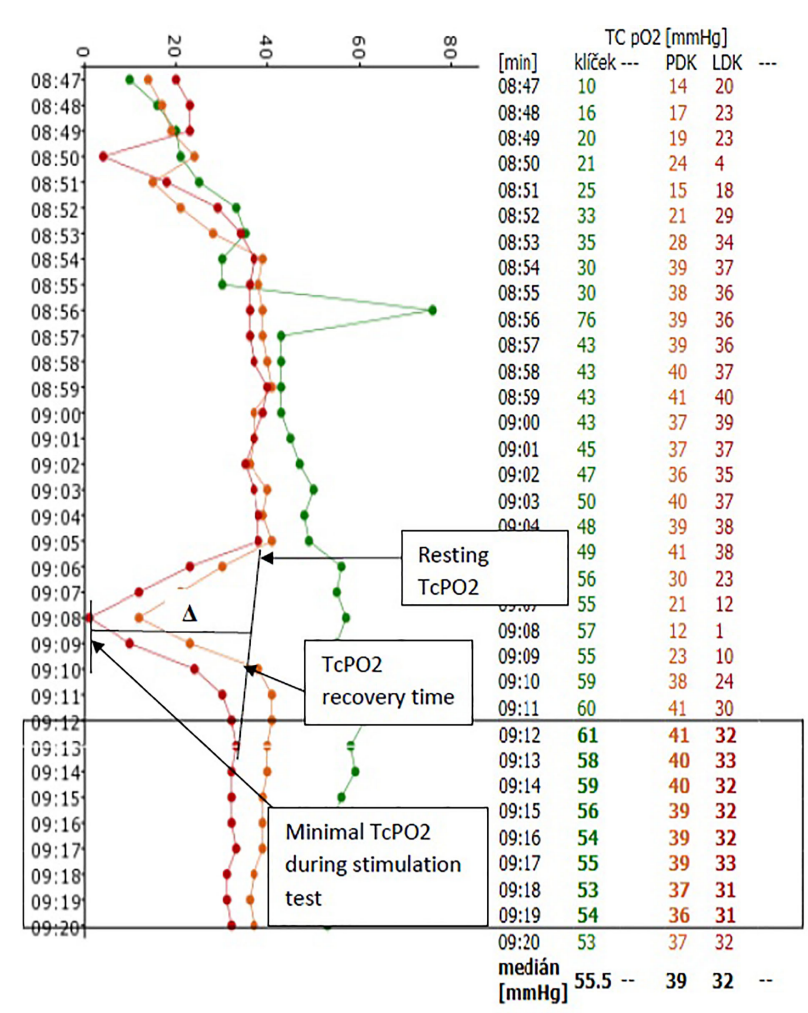

FIGURE 3 | Record of TCPO2 measurement during stimulation test Evaluated parameters: Resting TcPO2; maximal decline of TcPO2 during stimulation test, minimal TcPO2 during stimulation test; TcP02 differences in absolute numbers $(\triangle$ =resting TcPO2 minus minimal TcPO2 during the stimulation test) and in percentages; TcPO2 recovery time.

During the TcPO2 stimulation test, once patients attained a steady state verified by resting TcPO2 measurements, the lower limbs were elevated followed by maximal plantar and dorsal flexions. TcPO2 levels decreased in nearly all of the patients evaluated. However, in the group exhibiting monophasic flow or proven arterial obliteration in angiosomes, the decrease in TcPO2 was more noticeable $(>14 \mathrm{~mm} \mathrm{Hg}$ ) than in patients with triphasic flow. These findings are consistent with the results of the Audonnet study, which confirmed proximal arterial stenosis and a reduction in $\mathrm{TcPO} 2$ of $15 \mathrm{~mm} \mathrm{Hg}$ during a stimulation walking test (32). In our study, we found greater differences between groups in relation to the percentage of $\mathrm{TcPO} 2$ reduction and $\mathrm{TcPO} 2$ recovery time. In cases where arteries were obliterated or significantly stenotic, TcPO2 recovery lasted at least 7 minutes. However, TcPO2 recovery time during the $\mathrm{TcPO} 2$ stimulation test was significantly shorter (at around 6 minutes) in patients with physiological triphasic flow.

In contrast, to prove correlations with $\mathrm{ABI}$ and $\mathrm{TBI}$, resting TcPO2 did not correlate with impairment of large vessels, as confirmed by ultrasound findings. Indeed, the sensitivity of resting TcPO2 (approx. 48\%) was very low for PAD diagnosis. However, when TcPO2 measurements were augmented by the modified Ratchow test, the sensitivity and specificity of all TcPO2 stimulation parameters used to detect ischaemic lesions increased significantly by up to $25 \%$ and $11 \%$, respectively. Thus, the parameters for the TcPO2 stimulation test were comparable to the sensitivity and specificity of systolic pressure values for DPA, PTA (70\% and 64-71\%, respectively), ABIs (76\% and 69\%, respectively), TPs and TBIs (70-78\% and 75-78\%, respectively). According to our data analysis, PAD caused by arterial stenosis/ obliteration occurred most frequently in patients with $\mathrm{ABI} \leq 1.0$, $\mathrm{TP}<60 \mathrm{~mm} \mathrm{Hg}$ and TBI $<0.47$. These findings correspond mostly with the WIfI classification of DF patients. In patients with mild $\mathrm{PAD}$ of the lower limbs and with $\mathrm{ABI}<0.8$, sensitivity and specificity was $35-43 \%$ and $77-97 \%$, respectively; in patients with severe $\mathrm{PAD}$ and $\mathrm{ABI}<0.6$, sensitivity and specificity was 8 $16 \%$ and $96-97 \%$, respectively. Our findings for $\mathrm{TP}$ are also in line with recommendations (10).

The study has some limitations. There is a possibility that the patients we examined displayed either exhibited limited joint mobility or were not fully compliant with the foot exercises prescribed, two valid criteria for exclusion. However, these minor changes are not likely to have considerably interfered with results, since joint movement in different ranges does not affect the maximal effort exerted by the lower limb muscles when tensing and contracting (35). Indeed, maximal muscle activity in conjunction with leg elevation can lead to lower perfusion of acral and muscular tissues due to gravity. Further, we eliminated other factors that may have affected our final TcPO2 results by performing the test under tightly defined conditions, e.g. providing a calm environment and a sufficiently lengthy examination time, setting clearly defined leg elevations, maintaining an unvarying temperature in the room, and ensuring accurate probe placement $(18,36)$. Another limitation could be a relatively small number of enrolled patients or evaluated angiosomes but based on study power analysis all assessed parameters had in our study sufficient power - f.e. at least for $\Delta$ of $\mathrm{TcPO} 2$ was power of the study for $\mathrm{p}=0.05-85.6 \%$ and for \% decrease of TcPO2 85.6\%; respectively.

\section{CONCLUSION}

In conclusion, we found no association between resting $\mathrm{TcPO} 2$ and significant stenosis or obliteration of arteries supplying angiosomes, as verified by DUS wave analysis. The highest sensitivity and specificity for detecting stenotic/obliterated arteries were observed in cases where TcPO2 decreased $(\Delta)$ by more than $10 \mathrm{~mm} \mathrm{Hg}$ or by $23 \%$ in comparison to resting values. However, in terms of routine podiatry care, we assume the most important parameter to be $\mathrm{TcPO} 2$ recovery time. Recovery lasting more than 6 minutes correlated with a high probability of haemodynamically significant stenosis or obliteration in the arteries supplying the respective angiosomes. TcPO2 stimulation parameters not only correlated with indicators used for detecting alterations in large vessels, but also dramatically increased the sensitivity and specificity of $\mathrm{TcPO} 2$ measurement in relation to $\mathrm{PAD}$ detection. Therefore, this type of TcPO2 stimulation test is 
TABLE 5 | Sensitivity and specificity of microvascular assessment and TCPO2 parameters in relation to monophasic arterial flow supplying the relevant angiosome.

\begin{tabular}{|c|c|c|c|c|c|c|c|c|}
\hline $\begin{array}{l}\text { Evaluated } \\
\text { parameters } \\
\text { Determined } \\
\text { values }\end{array}$ & $\begin{array}{c}\text { Resting TcPO2 } \\
\text { sensitivity }(95 \% \mathrm{Cl})\end{array}$ & $\begin{array}{c}\text { Resting TcPO2 } \\
\text { specificity }(95 \% \mathrm{Cl})\end{array}$ & $\begin{array}{l}\text { Evaluated } \\
\text { parameter }\end{array}$ & $\begin{array}{l}\Delta \text { of TcPO2 sen- } \\
\text { sitivity }(95 \% \mathrm{Cl})\end{array}$ & $\begin{array}{c}\Delta \text { of TcPO2 specificity } \\
(95 \% \mathrm{Cl})\end{array}$ & $\begin{array}{l}\text { Evaluated } \\
\text { parameter }\end{array}$ & $\begin{array}{l}\% \text { decrease of TcPO2 } \\
\text { sensitivity }(95 \% \mathrm{Cl})\end{array}$ & $\begin{array}{l}\% \text { decrease of TcPO2 } \\
\text { specificity }(95 \% \mathrm{Cl})\end{array}$ \\
\hline$<30 \mathrm{~mm} \mathrm{Hg}$ & $0.0 \%(0.0-6.0)$ & $100 \%(93.3-100)$ & $\leq 0 \mathrm{~mm} \mathrm{Hg}$ & $100.0 \%(94-100)$ & $1.89 \%(0.05-10.1)$ & $\leq 0$ & $100.0 \%(94.0-100)$ & $1.89 \%(0.05-10.1)$ \\
\hline$\leq 33$ & $15 \%(7.1-26.6)$ & $88.7 \%(77-95.7)$ & $>0$ & $98.33 \%(91.1-100)$ & $5.66 \%(1.2-15.7)$ & $>0$ & $98.33 \%(91.1-100)$ & $5.6 \%(1.2-15.7)$ \\
\hline$\leq 35$ & $26.67 \%(16.1-39.7)$ & $84.91 \%$ (72.4-93.3) & $>3$ & $91.67 \%(81.6-97.2)$ & $16.98 \%(8.1-29.8)$ & $>5$ & $96.67 \%$ (88.5-99.6) & $11.32 \%(4.3-23)$ \\
\hline$\leq 38$ & $41.7 \%(29.1-55.1)$ & $67.92 \%(53.7-80.1)$ & $>5$ & $85 \%(73.4-92.9)$ & $32.08 \%(19.9-46.3)$ & $>8$ & $91.67 \%$ (81.6-97.2) & $18.87 \%(9.4-32)$ \\
\hline$\leq 43$ & $65 \%(51.6-76.9)$ & $33.96 \%$ (21.5-48.3) & $>10$ & $60 \%(46.5-72.4)$ & $67.92 \%(53.7-80.1)$ & $>17.8$ & $76.67 \%$ (64-86.6) & $39.62 \%(26.5-54)$ \\
\hline$\leq 45$ & $76.67 \%(64-86.6)$ & $26.42 \%(15.3-40.3)$ & $>13$ & $43.33 \%(30.6-56.8)$ & $75.47 \%(61.7-86.2)$ & $>20$ & $66.67 \%(53.3-78.3)$ & $52.83 \%(38.6-66.7)$ \\
\hline$\leq 48$ & $88.33 \%(77.4-95.2)$ & $11.32 \%(4.3-23)$ & $>15$ & $35 \%(23.1-48.4)$ & $81.13 \%(68-90.6)$ & $>23$ & $65 \%$ (51.6-76.9) & $62.26 \%(47.9-75.2)$ \\
\hline$\leq 50$ & $98.33 \%(91.1-100)$ & $1.89 \%(0.05-10.1)$ & $>18$ & $25 \%(14.7-37.9)$ & $84.91 \%(72.4-93.3)$ & $>25$ & $61.67 \%(48.2-73.9)$ & $62.26 \%(47.9-75.2)$ \\
\hline \multirow[t]{7}{*}{$\leq 51$} & $100 \%(94-100)$ & $0 \%(0-6.7)$ & $>20$ & $23.33 \%(13.4-36)$ & $86.79 \%(74.7-94.5)$ & $>30$ & $50 \%(36.8-63.2)$ & $73.58 \%(59.7-84.7)$ \\
\hline & & & $>24$ & $15 \%(7.1-26.6)$ & $88.68 \%$ (77.0-95.7) & $>35$ & $43.33 \%$ (30.6-56.8) & $79.25 \%$ (65.9-89.2) \\
\hline & & & $>29$ & $11.67 \%(4.8-22.6)$ & $96.23 \%(87-99.5)$ & $>40$ & $31.67 \%$ (20.3-45) & $84.91 \%$ (72.4-93.3) \\
\hline & & & $>35$ & $3.33 \%(0.4-11.5)$ & $98.11 \%(89.9-100)$ & $>60$ & $15 \%(7.1-26.6)$ & $86.79 \%(74.7-94.5)$ \\
\hline & & & $>39$ & $0 \%(0-6)$ & $100 \%(93.3-100)$ & $>100$ & $0 \%(0-6.0)$ & $100 \%(93.3-100)$ \\
\hline & Significance NS & Youden's J index 0.1157 & & $\begin{array}{l}\text { Significance } \\
p=0.0075\end{array}$ & Youden's J index 0.2792 & & Significance $p=0.0037$ & Youden's J index 0.2726 \\
\hline & AUC 0.541 & $\begin{array}{l}95 \% \text { confidence interval } \\
0.445 \text { to } 0.635\end{array}$ & & AUC 0.640 & $\begin{array}{l}95 \% \text { confidence interval } \\
0.545 \text { to } 0.728\end{array}$ & & AUC 0.651 & $\begin{array}{l}95 \% \text { confidence interval } \\
0.556 \text { to } 0.738\end{array}$ \\
\hline $\begin{array}{l}T C P O 2 \text {, transcutaneous oxys } \\
A \cup C \text {, area under the } R O C C\end{array}$ & $\begin{array}{l}\text { gen measurement; } \Delta \text {, diffe, } \\
\text { curve; the highest sensitivit }\end{array}$ & $\begin{array}{l}\text { rence of TCPO2 counted as resti } \\
t y \text { and specificity for individual } m\end{array}$ & $\begin{array}{l}\text { g TCPO2 minus } \\
\text { easurements ar }\end{array}$ & $\begin{array}{l}\text { minimal TcPO2 detectec } \\
\text { highlighted in bold. }\end{array}$ & d during stimulation test; \%, perc & entage; $p$, signifi & icance; $\mathrm{Cl}$, confidence interval, & nm Hg, millimetres of mercury; \\
\hline
\end{tabular}




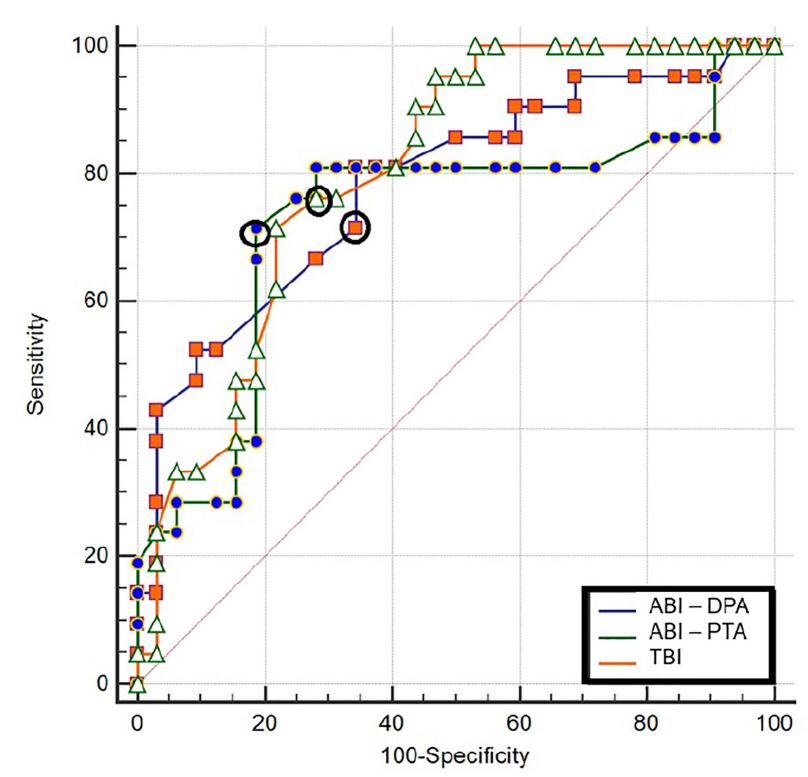

FIGURE 4 | Sensitivity and specificity of individual macrovascular assessment in relation to monophasic arterial flow supplying the relevant angiosome. ABI, ankle-brachial index; DPA, dorsalis pedis artery; PTA, posterior tibial artery; TBI, toe-brachial index; p, significance; $\mathrm{Cl}$, confidence interval; mm, Hg-millimetres of mercury; the highest sensitivity and specificity for individual measurements are highlighted in bold circles.

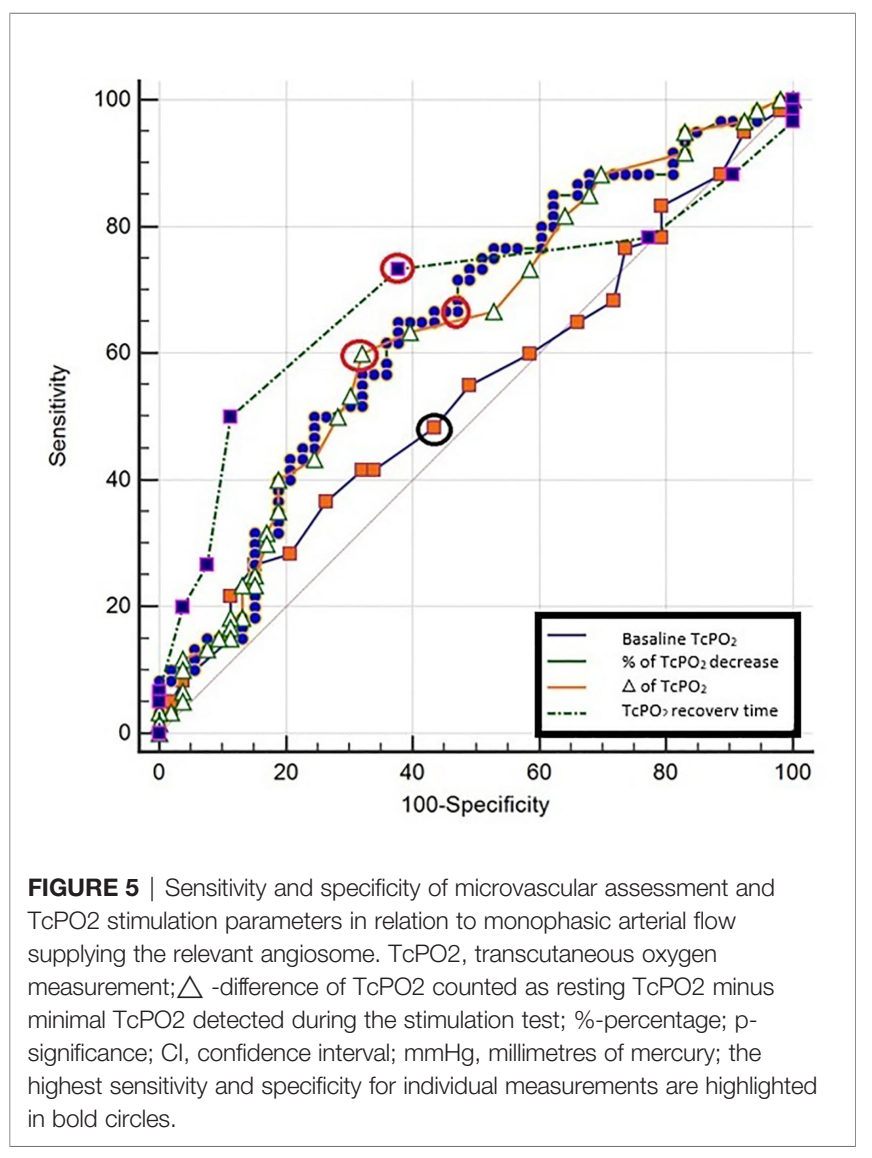

likely to be more accurate than the more common resting TcPO2 measurement at detecting latent forms of PAD or restenosis/ obliteration in DF patients with previous arterial intervention where macrocirculation parameters cannot always be properly assessed. As such, our novel test represents an easier and quicker non-invasive method of PAD assessment, helping to delay progression of local findings due to asymptomatic PAD in patients with DF.

\section{DATA AVAILABILITY STATEMENT}

The raw data supporting the conclusions of this article will be made available by the authors, without undue reservation.

\section{ETHICS STATEMENT}

The studies involving human participants were reviewed and approved by Ethics committees of the Institute for Clinical and Experimental Medicine and Thomayer Hospital. The patients/ participants provided their written informed consent to participate in this study.

\section{AUTHOR CONTRIBUTIONS}

JM and KR contributed to the study protocol and designed and reviewed the manuscript. $\mathrm{PP}, \mathrm{MF}, \mathrm{VW}, \mathrm{MD}$, and $\mathrm{JH}$ researched the data and reviewed the manuscript. EJ and AJ reviewed/edited the manuscript. $\mathrm{RB}$ reviewed the manuscript and VL performed the statistical analysis. All authors were equally entitled to query any aspect of the data, either directly or through independent analysis. AJ is the guarantor of the trial, retains full access to all data and assumes responsibility for the integrity and accuracy of the data analysed. All authors contributed to the article and approved the submitted version.

\section{FUNDING}

This study was supported by the Ministry of Health of the Czech Republic through grant NU20-01-00078 and its conceptual development of research organizations programme (Institute for Clinical and Experimental Medicine - IKEM, IN 00023001).

\section{ACKNOWLEDGMENTS}

We would like to thank Johana Venerová for contributing to the data and wish to acknowledge all of the podiatry nurses involved in the study, especially Marta Kř́žzová, Jitka Niklová, Hanka Tibenská, Jitka Bieliková and Markéta Kopecká. 


\section{REFERENCES}

1. Prompers L, Huijberts M, Apelqvist J, Jude E, Piaggesi A, Bakker K, et al. High Prevalence of Ischaemia, Infection and Serious Comorbidity in Patients With Diabetic Foot Disease in Europe. Baseline Results From the Eurodiale Study. Diabetologia (2007) 50(1):18-25. doi: 10.1007/s00125-006-0491-1

2. Morbach S, Furchert H, Groeblinghoff U, Hoffmeier H, Kersten K, Klauke G$\mathrm{T}$, et al. Long-Term Prognosis of Diabetic Foot Patients and Their Limbs. Diabetes Care (2012) 35(10):2021-7. doi: 10.2337/dc12-0200

3. Almuhannadi H, Ponirakis G, Khan A, Malik RA. Diabetic Neuropathy and Painful Diabetic Neuropathy: Cinderella Complications in South East Asia. J Pak Med Assoc (2018) 68(1):85-9.

4. Jude EB, Oyibo SO, Chalmers N, Boulton AJ. Peripheral Arterial Disease in Diabetic and Nondiabetic Patients: A Comparison of Severity and Outcome. Diabetes Care (2001) 24(8):1433-7. doi: 10.2337/diacare.24.8.1433

5. Jörneskog G. Why Critical Limb Ischemia Criteria Are Not Applicable to Diabetic Foot and What the Consequences Are. Scand J Surg (2012) 101 (2):114-8. doi: 10.1177/145749691210100207

6. Criqui MH, Aboyans V. Epidemiology of Peripheral Artery Disease. Circ Res (2015) 116(9):1509-26. doi: 10.1161/CIRCRESAHA.116.303849

7. Lange S, Diehm C, Darius H, Haberl R, Allenberg JR, Pittrow D, et al. High Prevalence of Peripheral Arterial Disease and Low Treatment Rates in Elderly Primary Care Patients With Diabetes. Exp Clin Endocrinol Diabetes (2004) 112(10):566-73. doi: 10.1055/s-2004-830408

8. Aziz ARA, Alsabek MB. Diabetic Foot and Disaster: Risk Factors for Amputation During the Syrian Crisis. J Diabetes Complications (2019) 26:107493. doi: 10.1016/j.jdiacomp.2019.107493

9. Fejfarová V, Bém R, Dubský M, Wosková V, Němcová A, Hazdrová J, et al. Novinky V Angiologii. Kazuistiky v diabetologii (2018) 16(suppl 1):S23-28.

10. Aboyans V, Ricco JB, Bartelink MEL, Björck M, Brodmann M, Cohnert T, et al. 2017 ESC Guidelines on the Diagnosis and Treatment of Peripheral Arterial Diseases, in Collaboration With the European Society for Vascular Surgery (ESVS): Document Covering Atherosclerotic Disease of Extracranial Carotid and Vertebral, Mesenteric, Renal, Upper and Lower Extremity Arteries. Endorsed by the European Stroke Organization (ESO) and the Task Force for the Diagnosis and Treatment of Peripheral Arterial Diseases of the European Society of Cardiology (ESC) and of the European Society for Vascular Surgery (ESVS). Eur Heart $J$ (2018) 39(9):763-816. doi: 10.1093/eurheartj/ehx095

11. Mills JLSr, Conte MS, Armstrong DG, Pomposelli FB, Schanzer A, Sidawy AN, et al. Society for Vascular Surgery Lower Extremity Guidelines Committee. The Society for Vascular Surgery Lower Extremity Threatened Limb Classification System: Risk Stratification Based on Wound, Ischemia, and Foot Infection (WIfI). J Vasc Surg (2014) 59(1):220-34.e1-2. doi: 10.1016/j.jvs.2013.08.003

12. Halliday A, Bax JJ. The 2017 ESC Guidelines on the Diagnosis and Treatment of Peripheral Arterial Diseases, in Collaboration With the European Society for Vascular Surgery (ESVS). Eur J Vasc Endovasc Surg (2018) 55(3):301-2. doi: 10.1016/j.ejvs.2018.03.004

13. Available at: https://iwgdfguidelines.org/wp-content/uploads/2019/05/ definitions-and-criteria-final.pdf.

14. Furuichi K, Shimizu M, Hara A, Toyama T, Wada T. Diabetic Nephropathy: A Comparison of the Clinical and Pathological Features Between the CKD Risk Classification and the Classification of Diabetic Nephropathy 2014 in Japan. Intern Med (2018) 57(23):3345-50. doi: 10.2169/internalmedicine.1132-18

15. IWGDF Guidelines.

16. Martini R, Abraham P. Transcutaneous PO2 Measurements. In: VAS European Book on Angiology/Vascular Medicine. Aracne (2018).

17. Urban M, Fouasson-Chailloux A, Signolet I, Colas Ribas C, Feuilloy M, Abraham P. Comparison of Two Devices for Measuring Exercise Transcutaneous Oxygen Pressures in Patients With Claudication. Vasa (2015) 44(5):355-62. doi: 10.1024/0301-1526/a000454

18. Nirala N, Periyasamy R, Kumar A. Noninvasive Diagnostic Methods for Better Screening of Peripheral Arterial Disease. Ann Vasc Surg (2018) 52:26372. doi: 10.1016/j.avsg.2018.03.018

19. Alexandrescu V, Hubermont G. The Challenging Topic of Diabetic Foot Revascularization: Does the Angiosome-Guided Angioplasty may Improve Outcome. J Cardiovasc Surg (Torino) (2012) 53(1):3-12.

20. Moosa HH, Peitzman AB, Makaroun MS, Webster MW, Steed DL. Transcutaneous Oxygen Measurements in Lower Extremity Ischemia:
Effects of Position, Oxygen Inhalation, and Arterial Reconstruction. Surgery (1988) 103(2):193-8.

21. Puricelli C, Tajana A, Kuntner A. [The Ratschow Test: Critical Study and Clinical Experiences]. Arch Ital Chir (1967) 93(1):673-96.

22. Karetová D, Staněk F. Angiologie Pro Praxi. Praha: Maxdorf (2001), 28-46.

23. Grouiller F, Jaquinandi V, Picquet J, Souday V, Saumet JL, Abraham P. Validation of a New Device for Transcutaneous Oxygen Pressure Recordings in Real and Simulated Exercise Tests. Int Angiol (2006) 25(2):190-6.

24. Brownrigg JR, Hinchliffe RJ, Apelqvist J, Boyko EJ, Fitridge R, Mills JL, et al. Performance of Prognostic Markers in the Prediction of Wound Healing or Amputation Among Patients With Foot Ulcers in Diabetes: A Systematic Review. Diabetes Metab Res Rev (2016) 32 Suppl 1:128-35. doi: 10.1002/dmrr.2704

25. Wang Z, Hasan R, Firwana B, Elraiyah T, Tsapas A, Prokop L, et al. A Systematic Review and Meta-Analysis of Tests to Predict Wound Healing in Diabetic Foot. J Vasc Surg (2016) 63(2 Suppl):29S-36S.e1-2. doi: 10.1016/ j.jvs.2015.10.004

26. Yang C, Weng H, Chen L, Yang H, Luo G, Mai L, et al. Transcutaneous Oxygen Pressure Measurement in Diabetic Foot Ulcers: Mean Values and Cut-Point for Wound Healing. J Wound Ostomy Continence Nurs (2013) 40 (6):585-9. doi: 10.1097/WON.0b013e3182a9a7bf

27. Hamburg NM, Creager MA. Pathophysiology of Intermittent Claudication in Peripheral Artery Disease. Circ J (2017) 81(3):281-9. doi: 10.1253/circj.CJ-16-1286

28. Jeffcoate WJ, Rasmussen LM, Hofbauer LC, Game FL. Medial Arterial Calcification in Diabetes and Its Relationship to Neuropathy. Diabetologia (2009) 52(12):2478-88. doi: 10.1007/s00125-009-1521-6

29. Available at: https://iwgdfguidelines.org/pad-guideline/.

30. Boyko EJ, Ahroni JH, Stensel VL, Smith DG, Davignon DR, Pecoraro RE. Predictors of Transcutaneous Oxygen Tension in the Lower Limbs of Diabetic Subjects. Diabetes Med (1996) 13(6):549-54. doi: 10.1002/(SICI)1096-9136 (199606) 13:6<549::AID-DIA126>3.0.CO;2-R

31. Puricelli C, Tajana A, Kuntner A. The Ratschow Test: Critical Study and Clinical Experiences. Arch Ital Chir (1967) 93(1):673-96.

32. Audonnet M, Signolet I, Colas-Ribas C, Ammi M, Abraham P, Henni S. Exercise Transcutaneous Oximetry of the Buttocks - External Validation With Computed Tomography Angiography. Circ J (2017) 81(8):1123-8. doi: 10.1253/circj.CJ-16-1316

33. Abraham P, Picquet J, Bouyé P, L'Hoste P, Enon B, Vielle B, et al. Transcutaneous Oxygen Pressure Measurements (Tcpo2) at Ankle During Exercise in Arterial Claudication. Int Angiol (2005) 24(1):80-8.

34. Kovacs D, Csiszar B, Biro K, Koltai K, Endrei D, Juricskay I, et al. Toe-Brachial Index and Exercise Test can Improve the Exploration of Peripheral Artery Disease. Atherosclerosis (2018) 269:151-8. doi: 10.1016/j.atherosclerosis. 2018.01.023

35. Héroux ME, Stubbs PW, Herbert RD. Behavior of Human Gastrocnemius Muscle Fascicles During Ramped Submaximal Isometric Contractions. Physiol Rep (2016) 4(17):e12947. doi: 10.14814/phy2.12947

36. Leenstra B, Wijnand J, Verhoeven B, Koning O, Teraa M, Verhaar MC, et al. Applicability of Transcutaneous Oxygen Tension Measurement in the Assessment of Chronic Limb-Threatening Ischemia. Angiology (2019) 6:3319719866958. doi: 10.1177/0003319719866958

Conflict of Interest: The authors declare that the research was conducted in the absence of any commercial or financial relationships that could be construed as a potential conflict of interest.

Publisher's Note: All claims expressed in this article are solely those of the authors and do not necessarily represent those of their affiliated organizations, or those of the publisher, the editors and the reviewers. Any product that may be evaluated in this article, or claim that may be made by its manufacturer, is not guaranteed or endorsed by the publisher.

Copyright (๑ 2021 Fejfarová, Matuška, Jude, Piťhová, Flekač, Roztočil, Wosková, Dubský, Jirkovská, Bém, Husáková and Lánská. This is an open-access article distributed under the terms of the Creative Commons Attribution License (CC BY). The use, distribution or reproduction in other forums is permitted, provided the original author(s) and the copyright owner(s) are credited and that the original publication in this journal is cited, in accordance with accepted academic practice. No use, distribution or reproduction is permitted which does not comply with these terms. 